Egyptian

Orthodontic Journal

\title{
ZYGOMATIC ANCHORAGE FOR MOLAR INTRUSION IN ADULT OPEN-BITE PATIENTS
}

\author{
Eiman S. Marzouk ${ }^{1}$; Essam M. Abdallah² \\ Walid A. El-Kenany'; Mohamed M. Fata ${ }^{3}$
}

ABSTRACT

Objective: The aim of this study is to investigate the effectiveness of the mini-plate zygomatic anchorage for intrusion of maxillary molars in adult skeletal anterior open-bite patients. Materials and Methods: The study group was composed of 10 anterior open-bite patients with posterior dentoalveolar excess. Placement of the mini-plates in the zygomatic buttress was carried out under local anaesthesia. After placement of a double T'PA, a closed $\mathcal{N i} i-T_{i}$ coil spring was placed bilaterally between the hook of the mini-plate just mesial and distal to the first molar buccal tube applying intrusive force of $450 \mathrm{~g}$ per side. Lateral cephalograms and posteroanterior radiographs were taken before intrusion (T1: post upper segmental leveling) and after intrusion (T2). The cephalometric films were measured and compared. Results: The mean amount of accomplished molar intrusion was $3.1 \mathrm{~mm} \pm 0.74 \mathrm{~mm}$, with a rate of $0.36 \mathrm{~mm}$ per month $\pm 0.08 \mathrm{~mm}$ per month and a bite closure of $6.55 \mathrm{~mm} \pm 1.83 \mathrm{~mm}$. Mandibular autorotation followed the molar intrusion, $S \mathcal{N B}$ and $S \mathcal{N}-$ Pog angles significantly increased while the $\mathcal{A N} B, \mathcal{M P}-S \mathcal{N}$ angle and $\mathcal{N}-S-G n$ angle significantly decreased. There was no significant buccal tip in the right and left molars. Conclusion: zygomatic anchorage can be used effectively for skeletal open-bite correction through posterior dento-alveolar intrusion.

Key Words: Zygomatic anchorage, open-6ite treatment, miniplates.

1- Lecturer Orthodontic Department, Alexandria University.

2- Professor Orthodontic Department, Alexandria University.

3- Professor, Maxillofacial and plastic Surgery Department, Alexandria University 
Egyptian

Orthodontic Journal

\section{INTRODUCTION}

Most orthodontists consider open bite, especially in adults, to be a significant treatment challenge. This malocclusion causes esthetic problems to the patient, impairs mastication and hinders speech.

Closing anterior open-bite is frequently performed by the extrusion of anterior teeth. However, this method is at stake for several reasons. First of all, anterior teeth in open-bite cases have short roots and less facial bony support. ${ }^{1}$ Incisor extrusion in adults might be destructive in this compromised area of the dentition due to root resorption. ${ }^{2}$ Also, extruded teeth are less stable than intruded teeth. ${ }^{3}$ Moreover, the extrusion of maxillary anterior teeth might compromise esthetic goals by causing excessive incisal and gingival display. ${ }^{4}$

An alternative treatment proposal for open bite closure is by applying intrusive forces to the posterior teeth. This can be achieved by relative intrusion of the posterior teeth either by interfering with or reducing the potential of molar eruption during the growth period (passive intrusion). ${ }^{5,6}$ On the other hand, in adult patients attempts are made to physically intrude the molars into their bony support (active intrusion). ${ }^{4,7}$

Various treatment methods were reported for the correction of anterior open-bites such as: high pull headgear, ${ }^{10-11}$ vertical-pull chincups ${ }^{6}$ vertical elastics, ${ }^{12-14}$ functional appliances ${ }^{15}$ and posterior bite-blocks. ${ }^{16-18}$ In addition to the tongue cribs, ${ }^{19}$ transpalatal arches, ${ }^{20}$ multiloop edgewise archwire. $^{8,21,22}$ More recently, repelling magnets ${ }^{23-28}$ have also been proposed for the treatment of vertical skeletal problems.

In all these traditional techniques, however, the correction was achieved primarily through extrusion of incisors or by preventing passive eruption of posterior teeth; these modalities cannot actively intrude the molars, especially in adult patients. Thus, surgical impaction of the maxillary posterior segment is considered to be the most effective treatment option to obtain counterclockwise rotation of the mandible and a reduction of anterior facial height in cases of skeletal anterior open-bite in adult patients with posterior dento-alveolar excess. ${ }^{29}$ The complexity, the risks of general anesthesia and the cost factor of surgical treatment have initiated a search for other less invasive clinical procedures. 
Egyptian

Orthodontic Journal

Accordingly, an alternative method is required to obtain vertical control by selective posterior intrusion, lacking unwanted anterior reaction forces and without dependence upon patient compliance or major surgical procedure or both. Several research workers ${ }^{4,30-34}$ introduced the zygomatic anchorage provided by the zygomatic buttress area as a valuable anchorage site to get effective intrusion of the maxillary posterior segment.

The aim of this clinical study is to verify the possibility of achieving true orthodontic intrusion of the posterior teeth, one of the most difficult orthodontic tooth movements, by using zygomatic anchorage and to evaluate the accompanying dental, skeletal and soft tissue changes that arise after intrusion of the maxillary molars in open-bite adult patients with dento-alveolar posterior excess, with special emphasis on the axial inclination of the intruded molars.

\section{MATERIALS AND METHODS}

\section{Patient Selection}

Ten patients with skeletal anterior open bite were enrolled in this study, which had refused orthognathic surgery and elected this less-invasive, miniplate-assisted orthodontic treatment. Selection criteria for the study were:

1. Anterior open bite patients, with age range 16-25 years with an open bite (as defined by cephalometric overbite measurement with at least $(-3 \mathrm{~mm})$ and a maximum of $(-8 \mathrm{~mm}))$.

2. Presence of maxillary posterior vertical dento-alveolar excess according to Burstone analysis. ${ }^{35}$

3. Acceptable or orthodontically correctable incisor-lip relations.

4. Absence of any systemic disease that may interfere with the surgery such as: uncontrolled Diabetes Mellitus or bleeding disorders.

The following methodology was accepted by the refereeing ethical committee prior to the start of the study. The patients and their parents have signed a written consent after accepting the purpose of the study including the surgical part. 
Egyptian

Orthodontic Journal

\section{The Surgical Procedure}

The surgical method as described by Erverdi et al ${ }^{32}$ was used with some modifications. After rinsing the mouth for one minute with $0.2 \%$ chlorhexidine gluconate, a local anesthetic was infiltrated bilaterally at the zygomatic buttress areas. A $1 \mathrm{~cm}$ transverse intra-oral incision extended from the second premolar to the first molar at the depth of the vestibular sulcus, above the attached gingival. The mucoperiosteal flap was elevated and the lower aspect of the zygomatic process was totally exposed by means of blunt dissection.

A pure titanium I-shaped multipurpose mini-plate (Gebrüder Martin $\mathrm{GmbH} \&$ Co. KG, Tuttlingen, Germany) was adjusted to fit the contour of the lower surface of each zygomatic buttress and it was fixed with three bone screws (Gebrüder Martin GmbH \& Co. KG, Tuttlingen, Germany) $7 \mathrm{~mm}$ in length (Figure 1 through 3 ).

The last hole of the mini-plate was exposed to the oral cavity from the incised wound. The exposed hole was sectioned distally to serve as a hook to receive the intrusive force. After fixing the plate the incision site was sutured (Figures 1 and 4).

Postoperatively, the patients were placed on an antibiotic (amoxicillin $500 \mathrm{mg}$ ) 1 capsule every 8 hours for 7 days, analgesic and anti-inflammatory medications (Ibuprofen $400 \mathrm{mg}$ ) one tablet every 8 hours for five days and chlorhexidine rinse $(0.12 \%)$ twice a day for a week. Ten days later the sutures were removed and the patients were instructed to brush the exposed part of their miniplates at least twice a day.

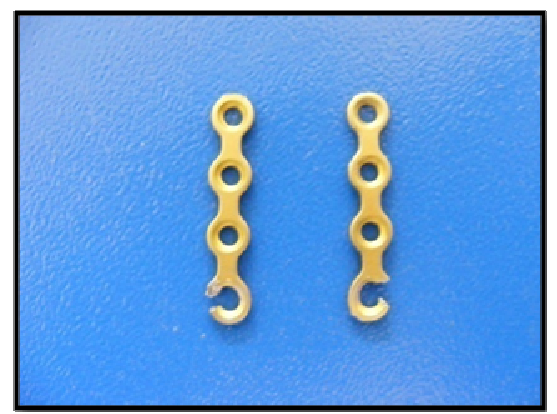

Figure 1:An I-shaped titanium mini-plate, last hole was cut opened to serve as a hook

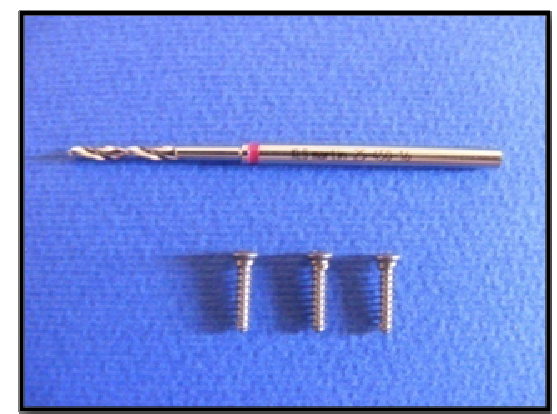

Figure 2: The miniscrews (7 mm length) and the pilot drill (1.5 mm diameter). 


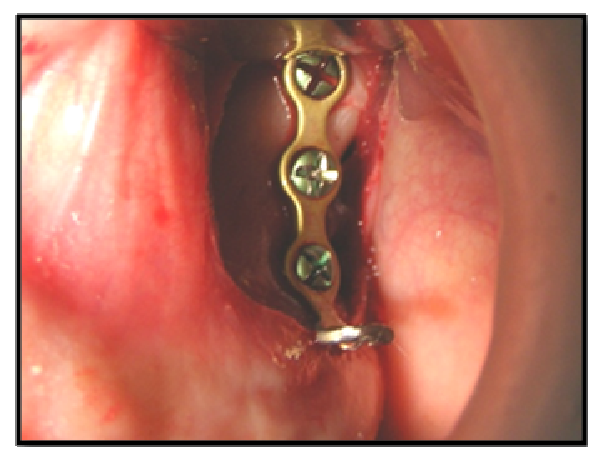

Figure 3: Fixation of the miniplate with three screws. Note the plate contouring.

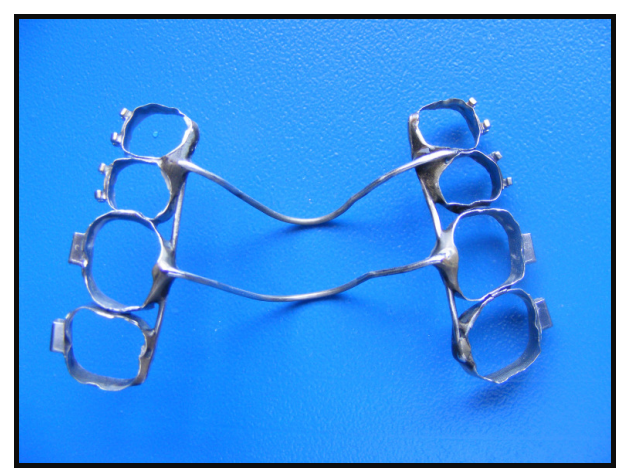

Figure 5: The double TPA.

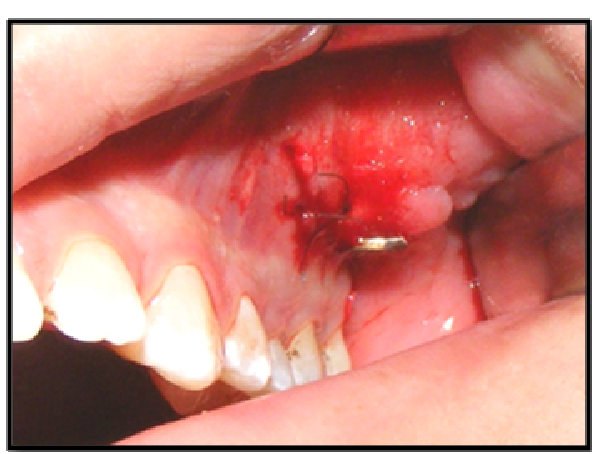

Figure 4: After fixing the plate the incision site was sutured and the hook is exposed.

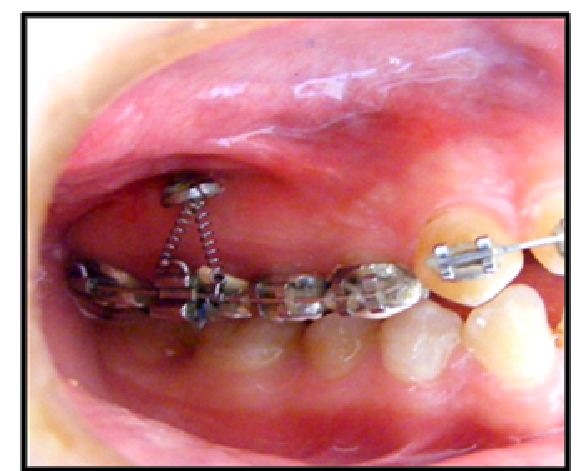

Figure 6: Ni-Ti coil springs were placed between the hook of the mini-plate and just mesial and distal to the first molar buccal tube.

\section{The orthodontic procedures}

Orthodontic leveling was carried out in three independent sections starting with light wires progressing to $0.016 \times 0.022$-inch sectional stainless steel arch wires.

A pilot study was done prior to the start of this research using a conventional single transpalatal arch with $1.5 \mathrm{~mm}$ wire gauge, but unfortunately this resulted in severe buccal tipping at the premolars and molars preventing closure of the open bite. This tipping was observed 
Egyptian

Orthodontic Journal

despite the fact that the posterior segments (first and second premolars and molars) were engaged with heavy stainless steel arch wire (0.017 $\times 0.025$-inch) from the buccal aspect. This may be due to the application of a heavy continous intrusion force of $450 \mathrm{gm}$ per side. Therefore, all patients in our study received a double transpalatal arch constructed from $1.2 \mathrm{~mm}$ stainless steel round wire to resist the buccal tipping of the molars during intrusion (Figure 5). The transpalatal arch was adapted four millimeters away from the palate to create sufficient room to accommodate the posterior impaction.

The insertion of this appliance was difficult because it necessitated taking an impression of eight well adapted bands on the right and left first and second premolars and molars and then cementation of these eight bands as one unit after fabrication of the appliance. Usually this was totally done in one long visit to avoid closure of the bands spaces.

Ni-Ti coil springs (GAC, Bohemia, NY, USA) were placed between the exposed hook of the mini-plate and just mesial and distal to the first molar buccal tube applying intrusive force of $450 \mathrm{gm}$ per side (Figure 6). The force was applied to the mini-plates two weeks after the surgery.

The patients were recalled each four weeks. The intrusion force was stopped when anterior over-bite reached $1-2 \mathrm{~mm}$. The molar intrusion was retained with vertical wire ligation between the tube of the first molar bands and the mini-plates throughout the subsequent orthodontic treatment.

One month before dehonding, the plates were surgically removed by loosening the screws from the zygomatic buttress area.

\section{Assessment of Cephalometric Measurements:}

The evaluation was carried out on lateral and postero-anterior cephalograms of the subjects taken before intrusion (T1: post upper segmental leveling) and after intrusion (T2).

1. Lateral cephalometric X-ray:- Several angular and linear measurements were taken to analyse the skeletal, dental and soft tissue changes (Figure 7).

Volume 41 - June 2012 
Egyptian

Orthodontic Journal

Since the sella (S) and nasion $(\mathrm{N})$ are a more reproducible landmarks and it is often difficult to locate Porion accurately, a constructed Frankfort horizontal plane (FHP) was drawn with an inferior angle of $7^{\circ}$ to $\mathrm{SN}$ plane through point $\mathrm{S}$ and a vertical line drawn from point $\mathrm{S}$ at $90^{\circ}$ to the constructed FHP served as the vertical plane of reference. ${ }^{36}$

2. Postero-anterior cephalometric X-ray:- was used to assess whether the molars were intruded bodily or with tipping by measuring the inner angle between the reference plane (i.e; a line joining ZL with ZR) and the axial inclination of the maxillary first molars. ${ }^{32,34}$ Where the ZL and ZR are the intersection between the zygomatico-frontal suture and orbit on the left and right sides, respectively).(Figure 8)

To assess the error of the cephalometric method, the radiographs were retraced 2 weeks after the first measurements by the same investigator. A paired-samples t-test was applied to the first and second measurements. It was found that the difference between the first and second measurements of the radiographs was insignificant. Any magnification in the lateral cephalometric radiograph was corrected in the measurements.

The statistical analysis was accomplished using Statistical Package for Social Sciences (version 17) software. Comparison between means before and after the intrusion was done using Wilcoxon Signed Ranks test (WSRT). The Pearson correlation coefficient was performed to study the correlation between the amount of intrusion and open-bite closure. The significance level was set at $\mathrm{P} \leq 0.05$.

\section{RESULTS}

The ten patients enrolled in this study had an age ranged from 16years 2 months to 22 years 9 months of age (mean 18 years and 8 months), they were 7 females and 3 males. Eight patients were Angle Class I and two were Angle Class II division 1.

In this study all miniplates remained functioning till the end of the treatment procedures. In only two patients, minimal mobility has been encountered in both sides. 
Egyptian

Orthodontic Journal

Regarding the patients' perception of the miniplates; the patients' chief complaints were minimal amount of pain that was relieved by prescribed analgesics and swelling that lasted for 5 to 6 days after placement. In general, the miniplates were well tolerated by the patients, no patient requested to have them removed.

The placement surgery was performed with the patients under local anesthesia and lasted on average between 20-30 minutes per plate.

All subjects underwent intrusion of the posterior dentoalveolar segment using Ni-Ti coil spring. The mean amount of accomplished molar intrusion was $3.1 \mathrm{~mm} \pm 0.74 \mathrm{~mm}$ (range: $2-4 \mathrm{~mm}$ ), with a rate of $0.36 \mathrm{~mm}$ per month $\pm 0.08 \mathrm{~mm}$ per month.

Comparison of the lateral cephalometric measurements at preintrusion and postintrusion is shown in Table 1. Figures 9 through 13 show the extra oral, intraoral photos and profile changes, in addition to the cephalmetric changes and the superimposition tracings of the first patient.

Regarding the skeletal changes, there was a significant increase in the $\mathrm{SNB}$ and SN-Pog angles with a mean of $1.5^{\circ} \pm 0.53^{\circ}$ and $1.6^{\circ} \pm 0.70^{\circ}$ respectively, while the ANB, MP-SN angle and N-S-Gn angle showed a significant decrease with a mean of $1.4^{\circ} \pm 0.52^{\circ}, 1.6^{\circ} \pm 1.84^{\circ}$ and $1.8^{\circ} \pm 0.42^{\circ}$ respectively. In addition to a significant reduction in the N-Me and ANS-Me lengths with a mean of $3.3 \mathrm{~mm} \pm 1.49 \mathrm{~mm}$ and $3 \mathrm{~mm} \pm 1.25 \mathrm{~mm}$ respectively.

In relation to the $\mathrm{SN}-\mathrm{Pog}$ angle, there was a significant decrease with a mean of $1.7^{\circ} \pm 0.67^{\circ}$.

Considering the dental measurements, the maxillary first molars were intruded with a mean of $3.1 \mathrm{~mm} \pm 0.74 \mathrm{~mm}$. In addition to a significant decrease in the over jet with a mean of $1.7 \mathrm{~mm} \pm 0.82 \mathrm{~mm}$.

On the other hand, there was a significant increase in the over-bite with a mean of $6.55 \mathrm{~mm} \pm 1.83 \mathrm{~mm}$. The pre-intrusion over-bite (range: $-8.5 \mathrm{~mm}$ to $-3 \mathrm{~mm}$ ) was corrected to reach $1-2 \mathrm{~mm}$ at post-intrusion. Also, there was a significant increase in the Occl pl-SN angle with a mean of $1.6^{\circ} \pm 0.84^{\circ}$. 
The results revealed no significant change in the incisors position; U1-FHP angle, L1-MP angle, L1-MP ( $\mathrm{mm}$ ) and U1-FHP (mm), except for a significant increase in the L1-FHP angle and the interincisal angle with a mean of $1.4^{\circ} \pm 1.43^{\circ}$ and $3.7^{\circ} \pm 2.11^{\circ}$ respectively.

Regarding the N'-Sn-Pog' angle, it showed a significant decrease with a mean of $2.3^{\circ} \pm 0.95^{\circ}$.

It was found that there was a highly significant positive correlation $\left(\mathrm{R}^{2}=0.7373\right)$ between the amount of intrusion and open-bite closure.

The following regression equation was anticipated:

$\mathrm{Y}=2.1139 \mathrm{X}$

Where Y: amount of over-bite closure ( $\mathrm{mm})$.

$\mathrm{X}$ : amount of molar intrusion (mm).

i.e.: If the molar was intruded by $1 \mathrm{~mm}$, the bite closes by $2.1139 \mathrm{~mm}$.

The results showed no statistically significant difference between the mean values of the pre and post intrusion axial inclination of the right or left upper first molars measured using postero-anterior cephalometric radiographs (Table 2 ).

\section{DISCUSSION}

The use of skeletal anchorage is a constantly evolving clinical technique that has the potential to facilitate the treatment of difficult to manage malocclusions. Most orthodontists consider open bite, especially in adults, to be a significant treatment challenge.

The upper arch was treated segmentally because most skeletal open bite malocclusions have a two-step maxillary occlusal plane with the step in the bicuspid/canine area. Placing a continuous arch wire in the brackets of a patient who has skeletal open bite leads to incisor extrusion and relapse over time because of the recoil pull of elastic and principal fibers on incisors. ${ }^{3}$

Although the miniplates were described as mobile in two patients throughout treatment, they were still sufficiently firm to provide the anchorage necessary to achieve the required intrusion. No plates were removed prematurely or replaced. 
There are various data on the design of the exposed part of the mini-plate. Various designs are available in the market. ${ }^{31,37-41}$ The coronal section of the titanium microplate used in this study is just a freely-accessible end perforation that was cut distally to resemble a hook, which suffices for simply attaching a coil spring to the molar band which ensures ease of cleaning and proper oral hygiene.

Regarding the skeletal measurements; mandibular autorotation following molar intrusion, caused forward and upward movement of point $\mathrm{B}$ and Pog which brought about significant sagittal changes in skeletal pattern, in addition to a significant reduction in the total and lower anterior facial height. These skeletal and soft tissue changes greatly enhanced the esthetics of skeletal open-bite non-growing patients, a result that cannot be achieved with traditional orthodontic techniques.

Our findings were in agreement with previous studies ${ }^{4,34,38,42-44}$ that also used skeletal anchorage. Concerning the amount of mandibular rotation, measured by the decrease in MP-SN. It was in accordance with the value reported by Erverdi et al ${ }^{32,34}$ but less than that of Sherwood et al, ${ }^{4}$ Xun et al ${ }^{42}$ and Erverdi et al. ${ }^{43}$ Regarding the significant decrease in the $\mathrm{N}-\mathrm{Me}$ and ANS-Me distance, this reduction matched closely the values of several researches ${ }^{4,38,43,44}$ but it was considered greater than that obtained by Xun et al. ${ }^{42}$

Considering the dental measurements, there was a significant increase in the overbite, in addition to a significant decrease in the overjet. A number of previous studies ${ }^{4,34,38,41,43,44}$ conducted on the treatment of open bite using skeletal anchorage showed similar results.

The pre-intrusion over-bite (range: $-8.5 \mathrm{~mm}$ to $-3 \mathrm{~mm}$ ) was successfully corrected to reach $1-2 \mathrm{~mm}$ at post-intrusion. Thus, it can be concluded that the use of zygomatic mini-plates to intrude the posterior segment, was useful for the treatment of severe anterior open-bite patients with openbite equal to or less than $8.5 \mathrm{~mm}$.

Mean while, the maxillary occlusal plane rotated in a clockwise direction following the intrusion of posterior teeth. This was monitored by a significant increase in the Occl pl-SN angle, which was in agreement with other studies. ${ }^{34,42}$

The results of the present study showed no significant changes in the incisors positions except for the significant increase in the lower incisal angle and interincisal angle. The significant increase in the L1-FHP angle 
and interincisal angle was due to the auto-rotation of the mandible following the posterior segment intrusion. This matches the results obtained by Erverdi et $\mathrm{al}^{43}$ who noted that no significant changes were observed in the incisor positions, except for interincisal angle, which increased. While, these results disagreed with Xun and colleagues ${ }^{42}$ who observed significant extrusion and retroclination in the upper incisors and insignificant extrusion and retroclination in the lower incisors immediately after the completion of the intrusion. This may be due to the continous rectangular stainless steel arch used during intrusion treatment in that study.

Furthermore, the counterclockwise rotation of the mandible as a result of molar intrusion also brought a dramatic improvement in the facial soft tissue convexity monitored by the significant decrease in the angle of convexity. This finding was consistent with the results obtained by Xun and colleages. ${ }^{42}$

The regression equation obtained in this study, stated that $1 \mathrm{~mm}$ of the molar intrusion results in a bite closure of $2.1139 \mathrm{~mm}$. Our results came in line with the well-known prosthodontic principle; each millimeter of molar intrusion yields a $2-3 \mathrm{~mm}$ closure of the anterior bite via mandibular autorotation. ${ }^{45}$

Only a small number of published studies ${ }^{32,34,46}$ have been concerned about the changes in the maxillary molar axial inclination following the intrusion. This is a crucial point, because once a significant buccal tip occurs, it burns out some of the achieved amount of molar intrusion by extuding the palatal cusps which would hinder the extent of open bite closure.

There was almost no buccal tipping observed in the present study, i.e: the molars were intruded bodily. While Erverdi and colleagues ${ }^{32}$ observed $7^{\circ}$ buccal tipping in the posterior teeth, they attributed that to the fact that the conventional palatal arch was not sufficiently rigid to withstand the buccal force. In another study by Erverdi and his coworkers $^{34}$ the measurements made on the postero-anterior cephalograms, showed that the maxillary molars were slightly tipped buccally, an average of $2.88^{\circ}$.

\section{CONCLUSION}

Skeletal open bite can be effectively corrected in nongrowing patients by this combined orthodontic and minimally invasive surgical approach, using 
zygomatic mini-plates as anchorage to intrude the maxillary molars, without the risks inherent with extruding incisors or major surgery.

Table 1. Comparison between pre-intrusion (T1) and post-intrusion (T2) mean values of the lateral cephalometric skeletal, dental and soft tissue measurements.

\begin{tabular}{|c|c|c|c|c|}
\hline & $\begin{array}{c}\text { Pre intrusion } \\
\text { Mean } \pm \text { SD }\end{array}$ & $\begin{array}{c}\text { Post intrusion } \\
\text { Mean } \pm \text { SD }\end{array}$ & $\begin{array}{l}\text { Difference } \\
\text { Mean } \pm \text { SD }\end{array}$ & $\mathbf{P}$ \\
\hline \multicolumn{5}{|l|}{ SKELETAL } \\
\hline SNA & $81.1 \pm 2.85$ & $81.1 \pm 2.85$ & 0 & $0.99 \mathrm{NS}$ \\
\hline SNB & $75.7 \pm 3.43$ & $77.2 \pm 3.26$ & $1.5 \pm 0.53$ & $0.001 *$ \\
\hline ANB & $5.4 \pm 2.32$ & $4 \pm 2.11$ & $-1.4 \pm 0.52$ & $0.001 *$ \\
\hline Angle of convexity N-A-Pog & $11.6 \pm 4.99$ & $9.9 \pm 4.58$ & $-1.7 \pm 0.67$ & $0.0012 *$ \\
\hline $\mathrm{N}-\mathrm{Me}(\mathbf{m m})$ & $125.4 \pm 6.92$ & $122.1 \pm 6.71$ & $-3.3 \pm 1.49$ & $0.0014 *$ \\
\hline ANS-Me (mm) & $77.4 \pm 5.68$ & $74.4 \pm 5.13$ & $-3 \pm 1.25$ & $0.013^{*}$ \\
\hline PP-SN angle & $9.2 \pm 2.30$ & $9.1 \pm 2.64$ & $-0.1 \pm 0.57$ & $0.2955 \mathrm{NS}$ \\
\hline MP-SN angle & $47.7 \pm 4.92$ & $46.1 \pm 5.00$ & $-1.6 \pm 1.84$ & $0.0312 *$ \\
\hline SN-Pog angle & $75.2 \pm 3.01$ & $76.8 \pm 2.57$ & $1.6 \pm 0.70$ & $0.001 *$ \\
\hline \multicolumn{5}{|l|}{ DENTAL } \\
\hline U6 to PP (mm) & $28.6 \pm 2.32$ & $25.5 \pm 2.01$ & $-3.1 \pm 0.74$ & $0.001 *$ \\
\hline OP-SN angle & $22.1 \pm 3.28$ & $23.7 \pm 3.33$ & $1.6 \pm 0.84$ & $0.0012 *$ \\
\hline U1-FHP angle & $116.7 \pm 7.44$ & $116.6 \pm 7.63$ & $-0.1 \pm 0.57$ & $0.2955 \mathrm{NS}$ \\
\hline L1-FHP angle & $45.8 \pm 5.57$ & $47.2 \pm 5.20$ & $1.4 \pm 1.43$ & $0.046^{*}$ \\
\hline L1-MP angle & $93.4 \pm 4.77$ & $93.2 \pm 4.66$ & $-0.2 \pm 0.42$ & $0.0839 \mathrm{NS}$ \\
\hline L1-MP (mm) & $43.3 \pm 2.79$ & $43.7 \pm 3.02$ & $0.4 \pm 0.70$ & $0.065 \mathrm{NS}$ \\
\hline U1-FHP (mm) & $74.1 \pm 5.26$ & $74 \pm 5.14$ & $-0.1 \pm 0.32$ & $0.171 \mathrm{NS}$ \\
\hline $\begin{array}{l}\text { Overbite(mm) } \\
\text { range }\end{array}$ & $\begin{array}{c}-4.95 \pm 2.03 \\
-8.5--3 \\
\end{array}$ & $\begin{array}{c}1.6 \pm 0.52 \\
1-2 \\
\end{array}$ & $6.55 \pm 1.83$ & $0.001 *$ \\
\hline Overjet (mm) & $5.15 \pm 2.64$ & $3.45 \pm 2.07$ & $-1.7 \pm 0.82$ & $0.0015 *$ \\
\hline Interincisal angle & $107.4 \pm 8.69$ & $111.1 \pm 8.70$ & $3.7 \pm 2.11$ & $0.002 *$ \\
\hline \multicolumn{5}{|l|}{ SOFT TISSUE } \\
\hline $\begin{array}{l}\text { Soft tissue facial convexity } \\
\text { N'-Sn-Pog' (angle) }\end{array}$ & $25.7 \pm 3.65$ & $23.4 \pm 2.91$ & $-2.3 \pm 0.95$ & $0.004 *$ \\
\hline
\end{tabular}

SD: Standard deviation.

NS: Not statistically significant. * Significance level $(\mathrm{P} \leq 0.05)$.

Difference: Mean difference between pre-intrusion and post-intrusion values. 
Table 2. Comparison between pre-intrusion (T1) and post-intrusion (T2) bucco-lingual inclination of the right and left upper first molars measured using postero-anterior cephalometric radiographs.

\begin{tabular}{|l|c|c|c|c|}
\hline $\begin{array}{l}\text { Bucco-lingual inclination } \\
\text { of the upper first molars }\end{array}$ & $\begin{array}{c}\text { Pre-intrusion } \\
\text { angle }\end{array}$ & $\begin{array}{c}\text { Post-intrusion } \\
\text { angle }\end{array}$ & Difference & P \\
\hline $\begin{array}{l}\text { Right molar } \\
\text { Mean } \pm \text { SD (degrees) }\end{array}$ & $100.4 \pm 2.72$ & $101.7 \pm 2.58$ & $1.3 \pm 0.82$ & $0.143 \mathrm{NS}$ \\
\hline $\begin{array}{l}\text { Left molar } \\
\text { Mean } \pm \text { SD (degrees) }\end{array}$ & $101.7 \pm 1.64$ & $102.8 \pm 1.55$ & $1.1 \pm 0.74$ & $0.07 \mathrm{NS}$ \\
\hline
\end{tabular}

SD: Standard deviation.

NS: Not statistically significant. * Significance level $(\mathrm{P} \leq 0.05)$.

Difference: Mean difference between pre-intrusion and post-intrusion angles in degrees.

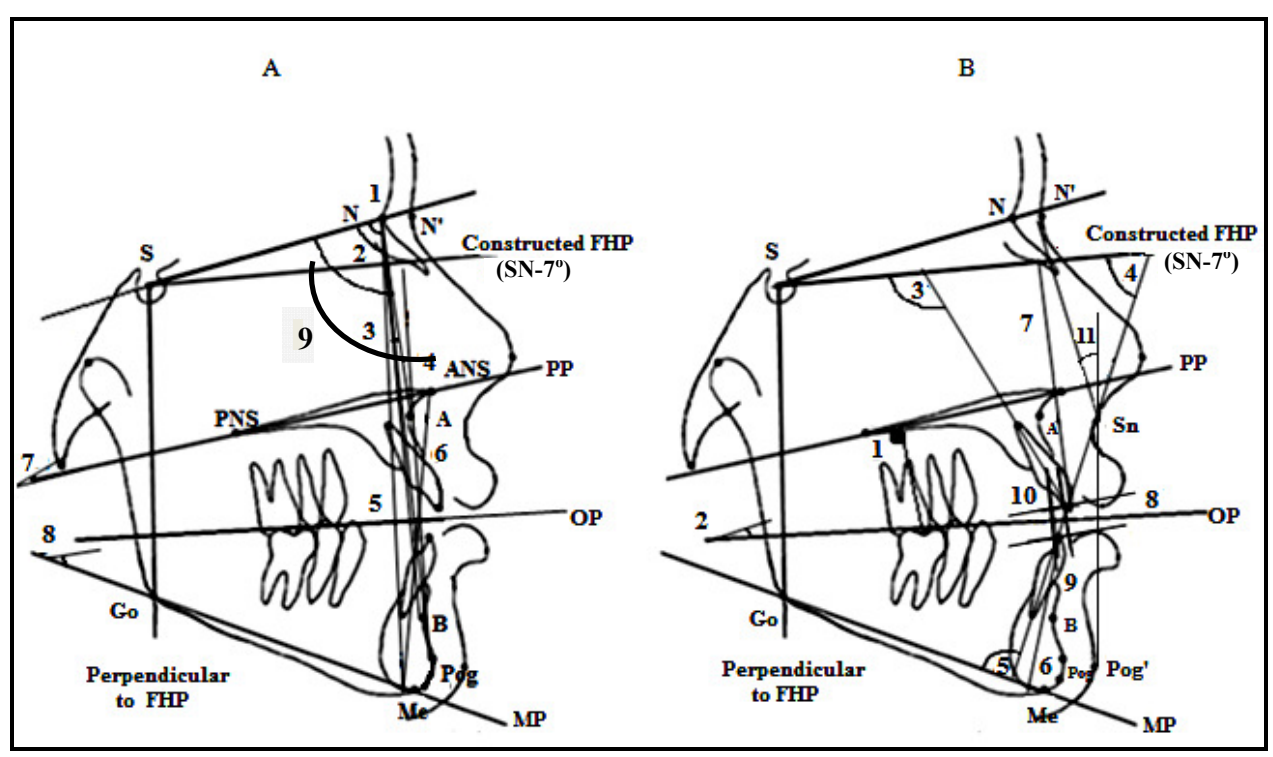

Figure 7: (A) Skeletal cephalometric measurements.1 indicates SNA; 2, SNB; 3, ANB; 4, N-A-Pog; 5, N-Me (mm); 6, ANS-Me (mm); 7, PP-SN angle; 8, MP-SN angle; 9, SN-Pog angle. (B) Dental and soft tissue cephalometric measurements. 1 indicates U6 to PP (mm); 2, OP-SN angle ; 3, U1-FHP angle; 4, L1-FHP angle; 5, L1-MP angle; 6, L1-MP (mm); 7, U1-FHP (mm); 8, Overbite; 9, Overjet; 10, Interincisal angle; 11, N'-Sn-Pog'. 


\section{Egyptian \\ Orthodontic Journal}

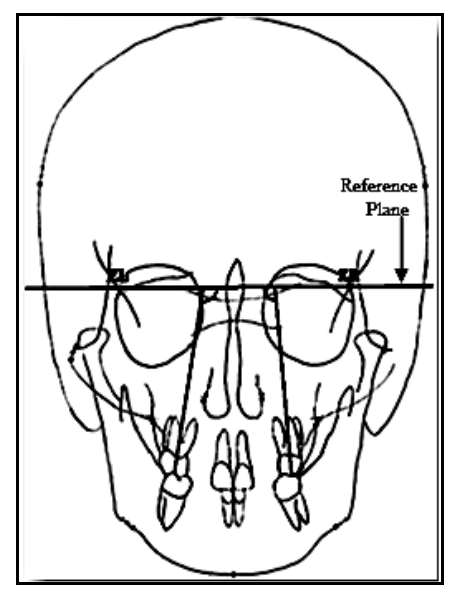

Figure 8: Reference plane and angles used in the postero-anterior cephalogram.
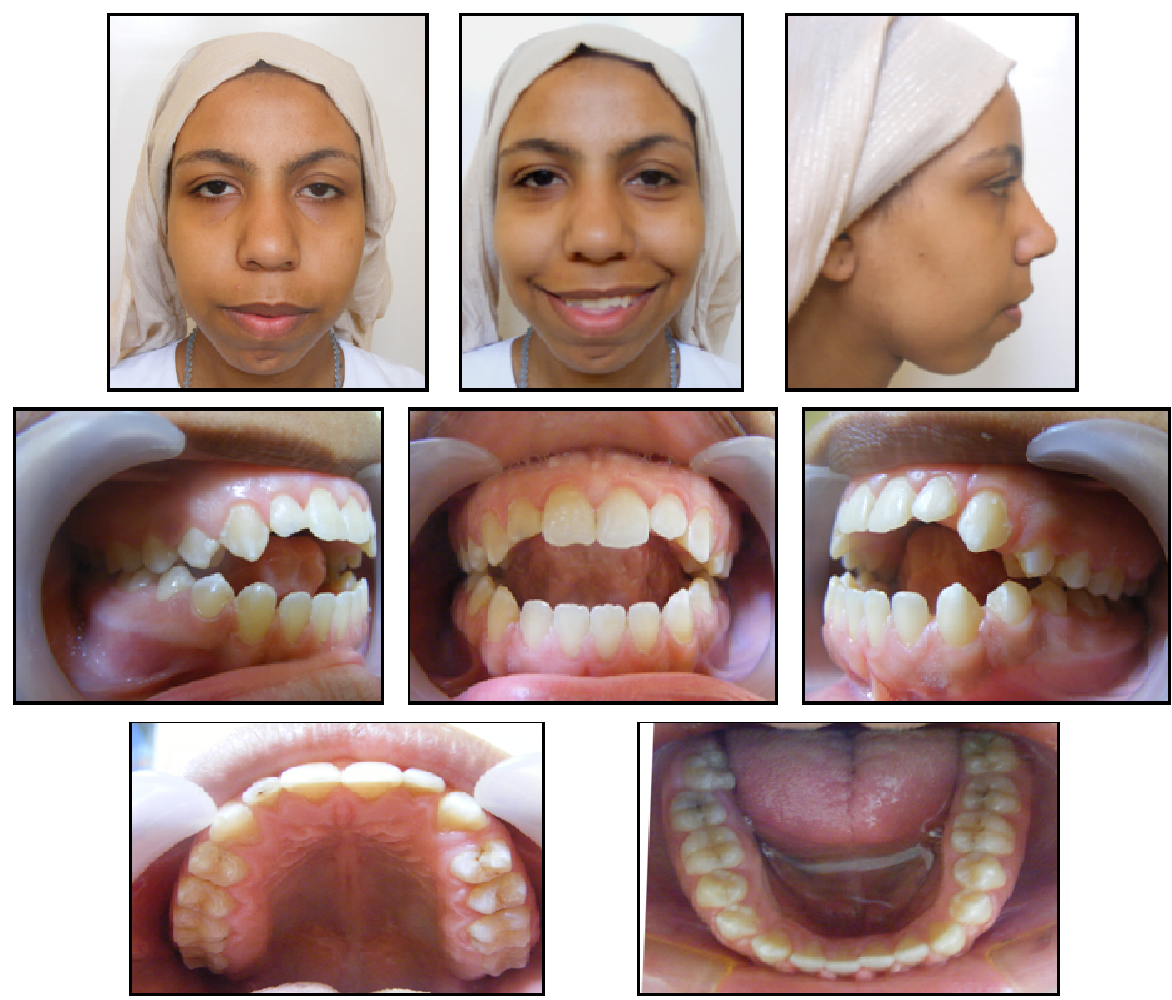

Figure 9: Pretreatment facial and intraoral photographs (case 1).

Volume 41 - June 2012 


\section{Egyptian \\ Orthodontic Journal}
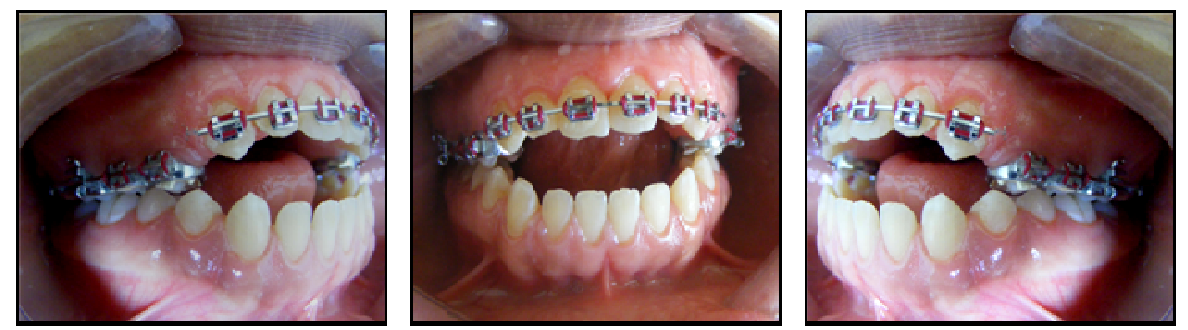

Figure 10: Intraoral photographs after segmental upper alignment $T 1$ (case 1).
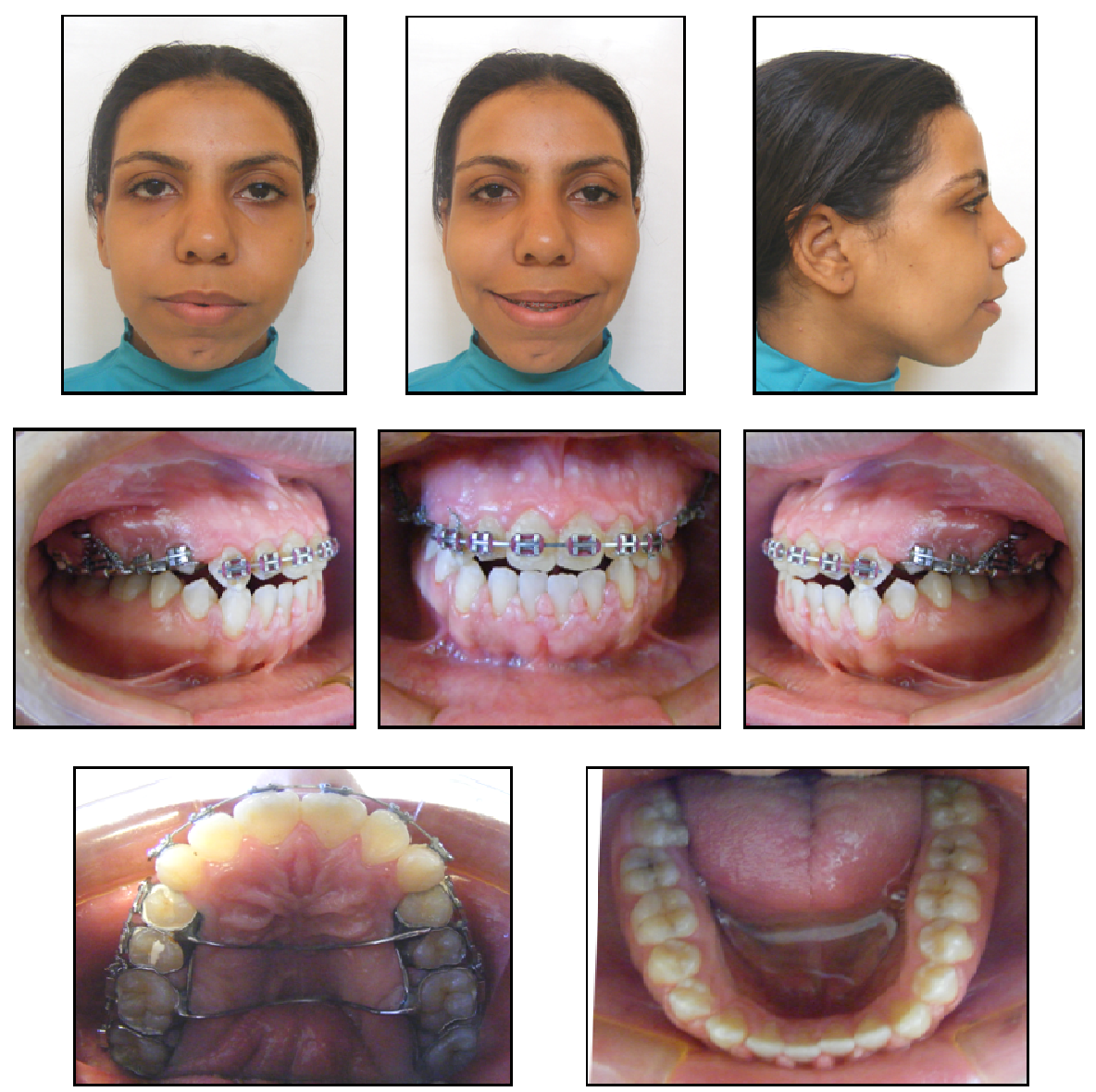

Figure 11: Facial and intraoral photographs at the end of intrusionat T2 (case 1).

Volume 41 - June 2012 


\section{Egyptian}

Orthodontic Journal
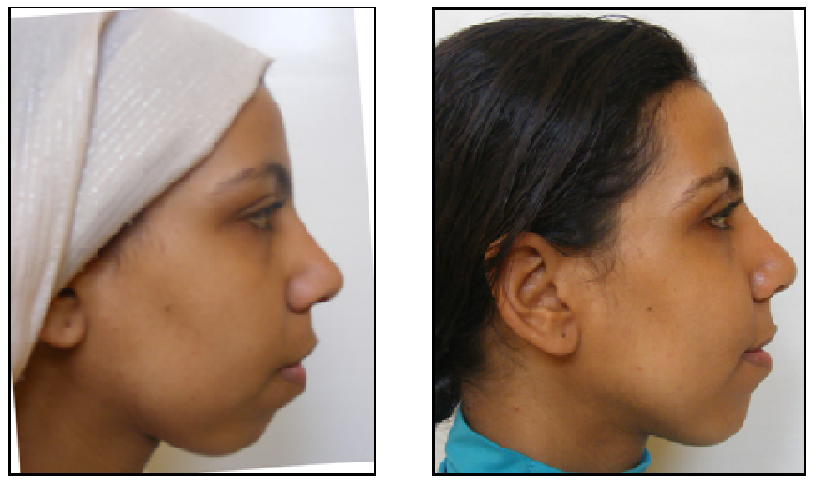

Figure 12: Profile view of case 1 before intrusion (left) and after intrusion (right).

A
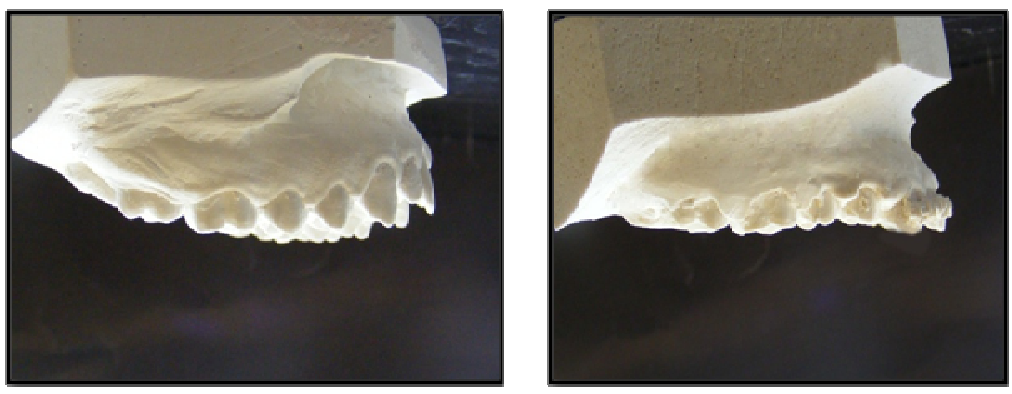

B
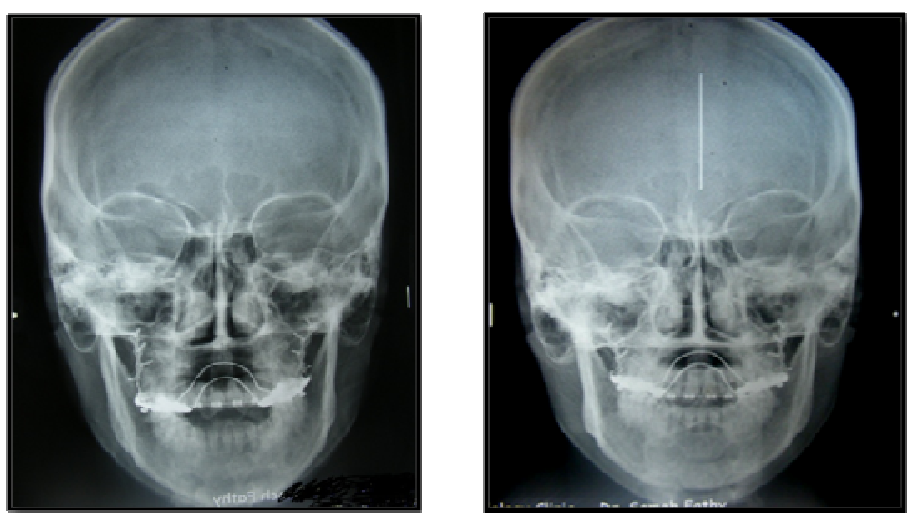

Volume 41 - June 2012 
C

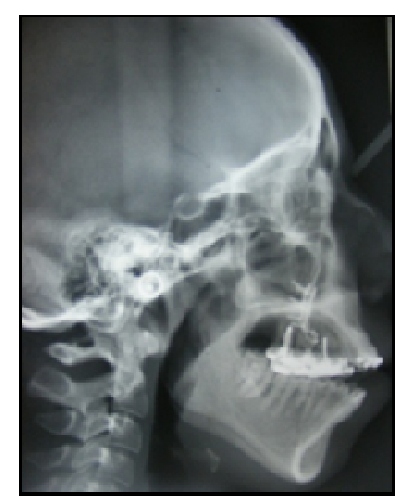

D

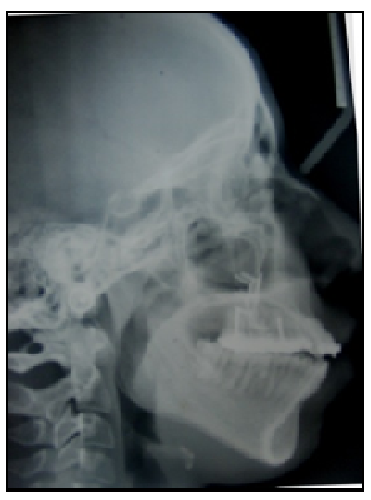

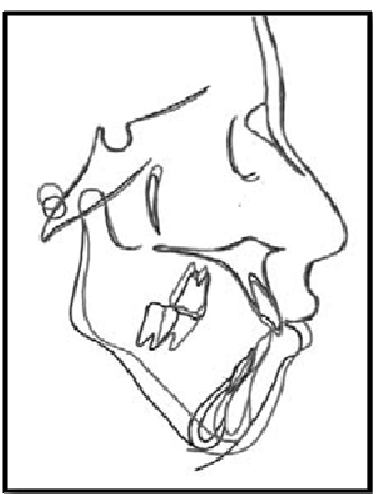

Figure 13: Comparison of pre-intrusion (left) and post-intrusion (right) of case 1. (A) Models. (B) Postero-anterior cephalograms. (C) Lateral cephalograms. (D) Pre-intrusion and post-intrusion superimposition.

\section{REFERENCES}

1. Harris EF, Butler ML. Patterns of incisor root resorption before and after orthodontic correction in cases with anterior open bites. Am J Orthod dentofacial Orthop. 1992; 101:112-9.

2. Graber TM. Orthodontics principles and practice. 3rd ed. Philadelphia: W. B. Saunders; 1972: 448-527.

3. Reitan K, Rygh P. Biomechanical principles and reactions. In: Graber TM, Vanarsdall RL, eds. Orthodontics current principles and techniques. 2nd ed. St Louis: Mosby; 1994:168-9.

4. Sherwood KH, Burch JG, Thompson WJ. Closing anterior open bites by intruding molars with titanium miniplate anchorage. Am J Orthod dentofacial Orthop. 2002;122:593-600.

5. Owen AM. Modified function regulator for vertical maxillary excess. J Clin Orthod. 1985;19:733-49.

6. Iscan HN, Dincer M, Gultan A, Meral O, Taner-Sarisoy L. Fffects of vertical chincup therapy on the mandibular morphology in open-bite patients. Am J Orthod Dentofacial Orthop. 2002; 122:506-11. 
7. Darendeliler MA, Yuksel S, Meral O. Open-bite correction with the magnetic activator device IV. JClin Orthod. 1995;29:569-76.

8. Chang YL, Moon SC. Cephalomtric evaluation of the anterior open bite treatment. Am J Onthod Dentofacial Orthop. 1999;115: 29-38.

9. Umemori M, Sugawara J, Mitani H, Nagasaka H, Kawamura H. Skeletal anchorage for open-bite correction. Am J Orthod Dentofacial Orthop. 1999;155:166-74.

10. Saito I, Yamaki M, Hanada K. Non surgical treatment of adult open bite using edge wise appliance combined with high pull head gear and Class III elastics. Angle Orthod. 2005; 75:277-83.

11. Proffit WR. Contemporary Orthodontics. 2nd ed. St Louis: Mosby; 1993:236-7.

12. Rinchuse DJ. Vertical elastics for correction of anterior open bite. J Clin Orthod. 1994;28:284.

13. Smith SS, Kucukkeles N, Acar A, Demirkaya A, Evrenol B, Enacar A. Cephalometric evaluation of open bite treatment with NiTi archwires and anterior elastics. Am J Orthod Dentofacial Orthop.1999;116:555-562.

14. Gehring D, Freeseman M, Fraziier M, Southard K. Extraction treatment of a Class II, Division 1 malocclusion with anterior openbite with headgear and vertical elastics. Am J Orthod Dentofacial Orthop. 1998;113:431-6.

15. Frankel R, Frankel C. A functional approach to treatment of skeletal open bite. Am J Orthod Dentofacial Orthop. 1983;84:54-68.

16. Kuster R, Ingervall $B$. The effect of treatment of skeletal open bite with two types of bile-blocks. Eur J Orthod. 1992;14:489-99.

17. Iscan HN, Akkaya S. The effects of the spring-loaded posterior bite block on the maxillo-facial morphology. Eur J Orthod.1992;14:54-60.

18. Insoft MD, Hocevar RA, Gibbs $\mathrm{CH}$. The nonsurgical treatment of a Class II openbite malocclusion. Am J Orthod Dentofacial Orthop. 1996;110:598-605. 
19. Huang GJ, Justus R, Kennedy DB, Kokich VG. Stability of anterior openbite treated with crib therapy. Angle Orthod. 1990;60: 17-24.

20. Hering K, Ruf S, Pancherz H. Orthodontic treatment of openbite and deepbite high-angle malocclusions. Angle Orthod. 1999;69: 470-7.

21. Kim YH. Anterior openbite malocclusion: nature, diagnosis and treatment by means of multiloop edgewise archwire technique. Angle Orthod. 1987;57:290-321.

22. Kim YH, Han UK, Lim DD, Serraon MLP. Stability of anterior open bite correction with multiloop edgewise archwire therapy: a cephalometric follow-up study. Am J Orthod Dentofacial Orthop. 2000;118:43-54.

23. Kalra V, Burstone CJ, Nanda R. Effects of a fixed magnetic appliance on the dentofacial complex. Am J Orthod Dentofacial Orthop. 1989;95:467-78.

24. Woods MG, Nanda RS. Intrusion of posterior teeth with magnets: an experiment in growing baboons. Angle Orthod. 1988;58:136-50.

25. Dellinger EL. A clinical assessmenl of the active vertical corrector: a nonsurgicl alternative for skeletal open-bite. Am J Orthod Dentofacial Orthop. 1986;89:428-36.

26. Kiliardis S, Egermark I, Thilander B. Anterior open bite treatment with magnets. Eur J Orthod. 1990;13:447-57.

27. Barbre RE, Sinclair PM. A cephalometric evaluation of anterior openbite correction with the magnetic active vertical corrector. Am J Orthod Dentofacial Orthop. 1991;61:93-102.

28. Darendeliler M, Yuksel S. Open-bite correction with the magnetic activator device IV. J Clin Orthod. 1995; 29:569-76.

29. Reyneke JP, Ferreti C. Anterior open bite correction by Le Fort 1 or bilateral sagittal split osteotomy. Oral Maxillofac Surg Clin North Am. 2007;19:321-38.

30. Sherwood KH, Burch JG. Skeletally based miniplate supported orthodontic anchorage. J Oral Maxillofac Surg. 2005;63:279-84. 
Egyptian

Orthodontic Journal

31. De Clerck H, Geerinckx V, Siciliano S. The Zygoma Anchorage System. J Clin Orthod. 2002;36:455-9.

32. Erverdi N, Tosun T, Keles A. A new anchorage site for the treatment of anterior open bite: zygomatic anchorage case report. World J Orthod. 2002;43:147-53.

33. Erverdi N, Usumez S, Solak A. New generation open-bite treatment with zygomatic anchorage. Angle Orthod. 2006;76:519-26.

34. Erverdi N, Keles A, Nanada R. The use of skeletal anchorage in open bite treatment: A cephalometric evaluation. Angle Orthod. 2004; 74:381-90.

35. Burstone CJ, James RB, Legan H, Murphy GA, Norton LA. Cephalometrics for orthognathic surgery. J Oral Surg.1978;36:269-77.

36. Baumrind S, Miller D, Molthen R. The reliability of head film measurements: 3. Tracing superimposition. Am J Orthod. 1976 ;70:617-44.

37. Sherwood K. Correction of Skeletal Open Bite with Implant Anchored Molar/Bicuspid Intrusion. Oral Maxillofacial Surg Clin N Am. 2007; 19: 339-50.

38. Akay MC, Aras A, Günbay T, Akyalçın S, Koyuncue BÖ. Enhanced Effect of Combined Treatment With Corticotomy and Skeletal Anchorage in Open Bite Correction. J Oral Maxillofac Surg. 2009; 67:563-9.

39. Sugawara J, Daimaruya T, Umemori M, et al. Distal movement of mandibular molars in adult patients with the skeletal anchorage system. Am J Orthod Dentofacial Orthop. 2004;125:130-38.

40. Kircelli B, Pektas Z. Midfacial protraction with skeletally anchored face mask therapy: A novel approach and preliminary results. Am J Orthod Dentofacial Orthop. 2008;133:440-9.

41. Cornelis MA, Scheffler NR, Mahy P, Siciliano S, De Clerck HJ, Tulloch JFC. Modified Miniplates for Temporary Skeletal Anchorage in Orthodontics: Placement and Removal Surgeries. J Oral Maxillofac Surg. 2008;66:1439-45.

42. Xun C, Zeng X, Wang X. Microscrew anchorage in skeletal anterior openbite treatment. Angle Orthod. 2007;77:47-56. 
43. Erverdi N, Usumez S, Solak A, Koldas T. Noncompliance Open-Bite Treatment with Zygomatic Anchorage. Angle Orthod. 2007;77:986-90.

44. Kuroda S, Sakai Y, Tamamura N, Deguchi T, Takano-Yamamoto T. Treatment of severe anterior open bite with skeletal anchorage in adults: Comparison with orthognathic surgery outcomes. Am J Orthod Dentofacial Orthop. 2007;132:599-605.

45. Kuhn R. Control of anterior vertical dimension and proper selection of extraoral anchorage. Angle Orthod. 1968;38:340-9.

46. Yao CJ, Lee J, Chen H, Chang ZJ, Chang H, ChenY. Maxillary molar intrusion with fixed appliances and mini-implant anchorage studied in three dimensions. Angle Orthod. 2005;75:754-60. 